\title{
Message from the Editors to our Reviewers - Thank you for your support
}

The Editors of Cardiology Journal very much appreciate the assistance of our reviewers in making the Journal a better forum for research and education in cardiology worldwide. The constructive reviews provided to our authors are extremely valuable. We understand the burden this work places on our reviewers. We are working to further facilitate the review process to technically make as easy as possible.

The Journal's national and international pool of reviewers has been increasing systematically over recent years. So too are the number of submissions to the Journal which are also growing. So if you are interested in joining, please send us an e-mail with your areas of expertise and interest, and a short bio.

We are grateful to all our reviewers for any contribution to the works of the Journal in the past and very specifically in 2020. Those reviewers who have provided three or more reviews last year are listed below. The full list is available at our website.

Editorial Team

Cardiology Journal

\section{Most active Reviewers of $\mathbf{2 0 2 0}$}

\author{
Francisco Calvo-Iglesias (Spain) \\ Javier Castrodeza (Spain) \\ Wei Cheng (United States) \\ Miao Chu (China) \\ Carlos Cortés (Spain) \\ Michael Czekajlo (United States) \\ Alicja Dąbrowska-Kugacka (Poland) \\ Iwona Gorczyca (Poland) \\ Piotr Jankowski (Poland) \\ Agnieszka Kapłon-Cieślicka (Poland) \\ Yongcheol Kim (South Korea) \\ Maciej Lesiak (Poland) \\ Javier Lopez-Pais (Spain) \\ Jarosław Meyer-Szary (Poland) \\ Jesus Peteiro (Spain) \\ Silvia Samarin (Slovenia) \\ Kaori Shinchi (Japan) \\ Philipp Sommer (Germany) \\ Radosław Targoński (Poland)
}

This article is available in open access under Creative Common Attribution-Non-Commercial-No Derivatives 4.0 International (CC BY-NC-ND 4.0) license, allowing to download articles and share them with others as long as they credit the authors and the publisher, but without permission to change them in any way or use them commercially. 
